\title{
Extensive personal experience. Validation of prolactin levels in menstrual disorders and in prolactinomas
}

\author{
Menelaos L. Batrinos
}

Athens University Medical School, Athens, Greece

It is now well established that hyperprolactinaemia is not rare and in the majority of cases is caused by a pituitary tumor, a prolactinoma..$^{1-4}$ However, despite a plethora of relevant publications there are still certain questions that have not been adequately addressed: 1 . What is the upper normal level of serum prolactin beyond which the condition should be characterized as hyperprolactinaemia requiring evaluation by imaging. 2 . What is the incidence of non-secreting adenomas of the pituitary that might be erroneously regarded as prolactinomas. 3 . How long should medical treatment be continued in the case of a prolactinoma. In this communication an attempt is made to critically analyze results on prolactinaemia obtained in our laboratory over a long time period, a sort of "meta-analysis" of our previously published data, ${ }^{5,6}$ aiming at reaching certain conclusions with practical implications for the clinician. Particular emphasis is placed on the prolactin levels in various menstrual disorders observed in 2500 women.

The serum prolactin (PRL) level that warrants imaging investigation is controversial. Some authors

Key words: Galactorrhoea, Hyperprolactinaemia, Menstrual disorders, Prolactinomas

Address for correspondence:

Menelaos L. Batrinos, Emeritus Professor of Endocrinology,

Athens University Medical School, Athens, Greece,

e-mail: bithrini@ath.forthnet.gr

Received 03-07-09, Revised 20-08-09, Accepted 10-09-09 suggest evaluation only if the PRL value is $>50$ or $>100 \mu \mathrm{g} / \mathrm{L}$, whereas most investigators rely on the upper limit of the reference range quoted in the commonly used commercial assays. These assays, however, are based on measurements performed in a limited number of persons and for this reason many Endocrine Centers prefer to create reference ranges of serum prolactin values based on their own normal or patient populations, a routine that has also been our policy. During a period of 12 years we have measured serum prolactin along with other hormones in 4199 women aged 14 to 43 years who presented at the Endocrine Unit of the Department of Pharmacology of the Athens Medical School with various endocrine disorders (Table 1).

Of the 4199 women, 753 who were examined for infertility of the couple due mainly to male infertility had normal cycles and no clinically manifest endocrine disorder and can be considered as a sample of the normal population. The distribution frequency of serum prolactin values in this group shows a bellshaped curve positively skewed with $94.8 \%$ of the values between 1 and $20 \mu \mathrm{g} / \mathrm{L}$ and a tail of scattered values up to $30 \mu \mathrm{g} / \mathrm{L}$. In the 11 cases with prolactin between 30 and $50 \mu \mathrm{g} / \mathrm{L}$ three prolactinomas were found, while three of the four cases with prolactin over $50 \mu \mathrm{g} / \mathrm{L}$ had a prolactinoma (Figure 1).

Five hundred and nineteen patients examined for hirsutism with normal ovulatory cycles showed the same pattern of frequency distribution of prolactin, with $95.5 \%$ of the values within the range of 1 to $20 \mu \mathrm{g} / \mathrm{L}$ and a few values over $20 \mu \mathrm{g} / \mathrm{L}$ in which no 
Table 1. Frequency of prolactin values of more than $30 \mu \mathrm{g} / \mathrm{L}$ and incidence of prolactrinomas at this range of values.

\begin{tabular}{lccc}
\hline & $\begin{array}{c}\text { Number } \\
\text { of patients }\end{array}$ & $\begin{array}{c}\text { Prolactin values }>\mathbf{3 0} \boldsymbol{\mu g} / \mathbf{L} \\
\mathbf{n}(\boldsymbol{\%})\end{array}$ & $\begin{array}{c}\text { Prolactinoma } \\
\mathbf{n}(\boldsymbol{\%})\end{array}$ \\
\hline 1. Women consulting for infertility of the couple & 753 & $15(2)$ & $6(40)$ \\
2. Idiopathic hirsutism & 519 & $5(0.96)$ & $0(0)$ \\
3. Menstrual disorders & 2523 & $77(3)$ & $32(41)$ \\
a. Primary amenorrhoea & 398 & $3(6.75)$ & $2(66.6)$ \\
b. Primary oligomenorrhoea & 887 & $19(2.1)$ & $6(31.5)$ \\
c. Secondary oligomenorrhoea & 553 & $18(3.2)$ & $6(33.3)$ \\
d. Secondary amenorrhoea & 392 & $32(8.16)$ & $14(43)$ \\
e. Functional uterine bleeding & 221 & $3(1.3)$ & $3(100)$ \\
f. Hypomenorrhoea & 72 & $2(2.7)$ & $1(50)$ \\
4. Galactorrhoea & 404 & $116(28.7)$ & $79(68)$ \\
a. With normal menses & 201 & $30(15)$ & $8(26.6)$ \\
b. with menstrual disorders & 203 & $86(42.3)$ & $71(82.5)$ \\
\hline
\end{tabular}

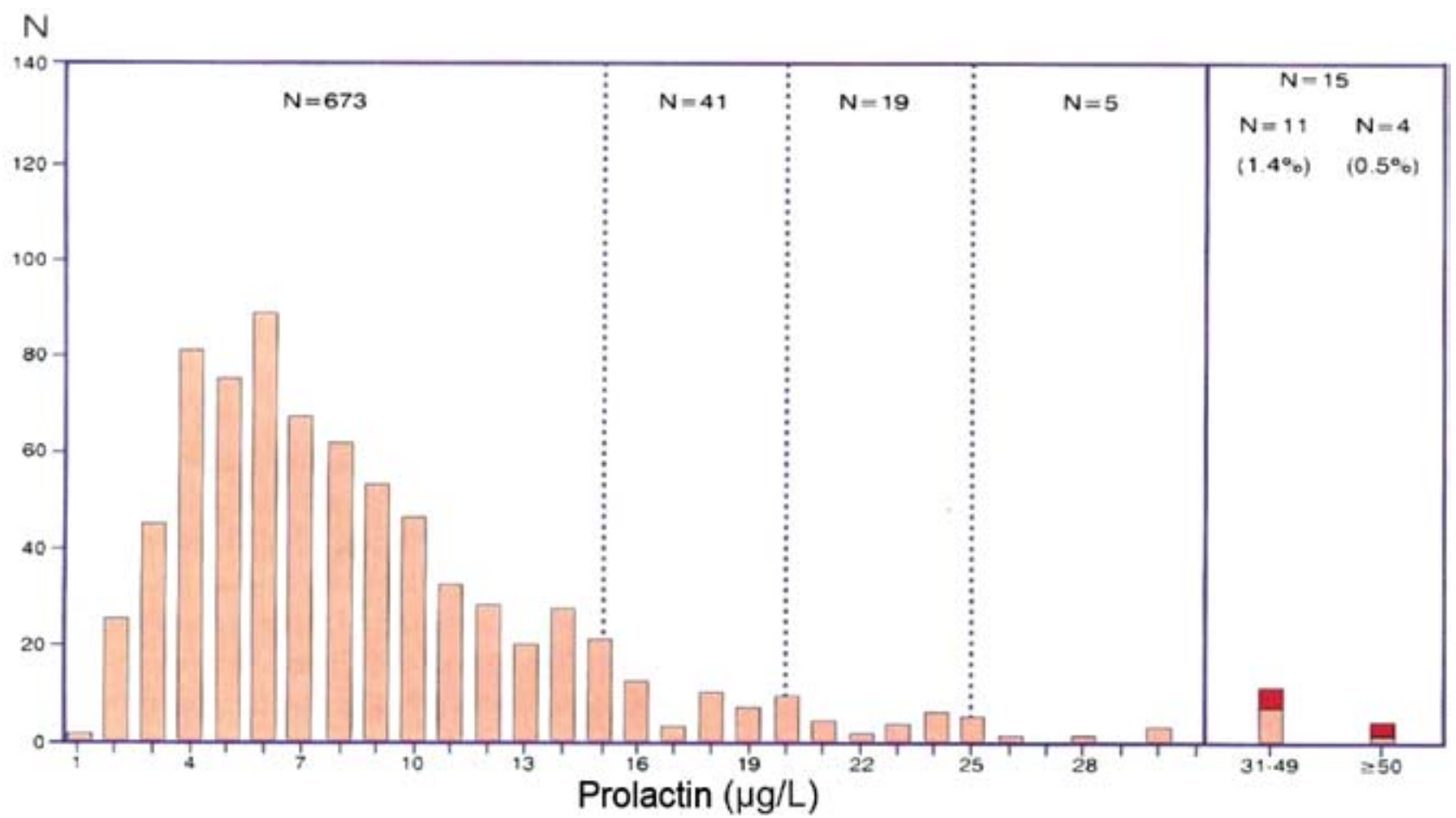

Figure 1. Distribution of prolactin values in 753 women with normal cycles investigated for infertility. The red part of the columns indicates the number of prolactinomas.

prolactinoma was found (Figure 2).

It is of interest that a strikingly similar frequency distribution of values was observed in the 2523 women with various types of menstrual disorders with the same percentage of values within the range of 1 to $20 \mu \mathrm{g} / \mathrm{L}(94.4 \%)$, again $2.5 \%$ of the values extending up to $30 \mu \mathrm{g} / \mathrm{L}$ and a subset of 77 values $(3 \%)$ above $30 \mu \mathrm{g} / \mathrm{L}$, half of them with values from 30 to $49 \mu \mathrm{g} / \mathrm{L}$ in which six prolactinomas were found and the other half with values above $50 \mu \mathrm{g} / \mathrm{L}$ in which 26 prolactinomas were observed (Figure 3 ). The assumption of a range of prolactin values over $30 \mu \mathrm{g} / \mathrm{L}$ in which the 


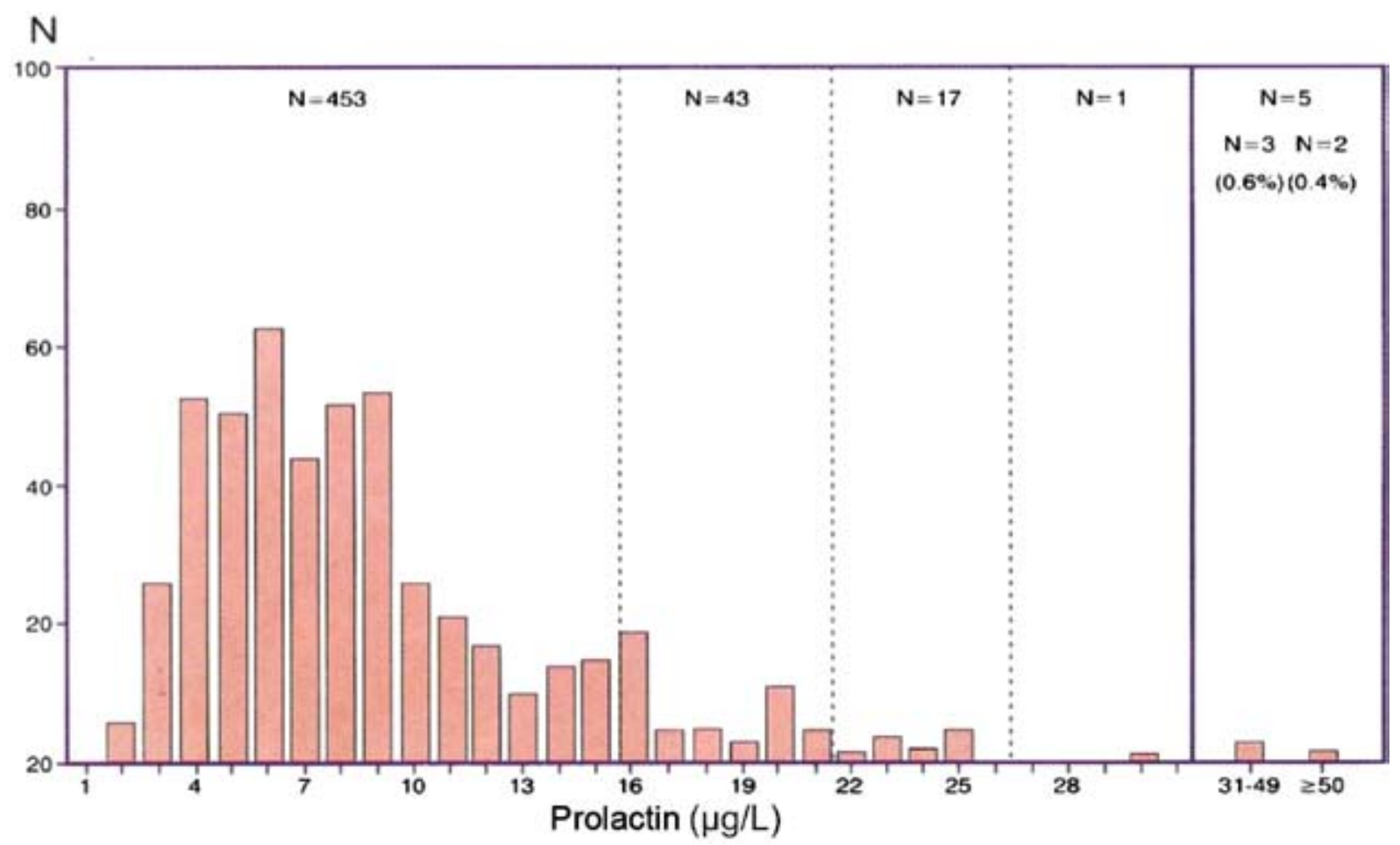

Figure 2. Distribution of prolactin values in 519 women with normal menses and hirsutism.

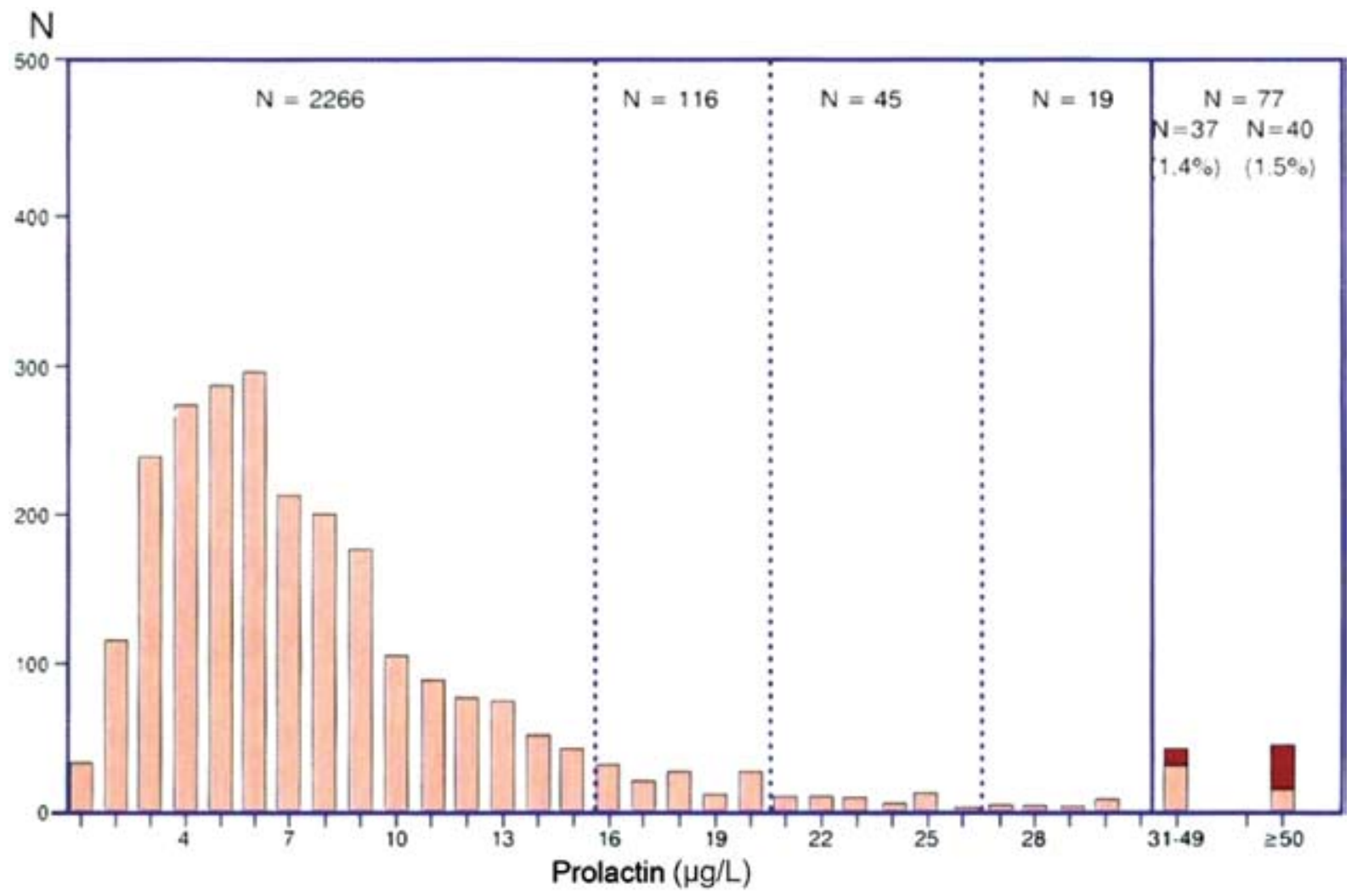

Figure 3. Distribution of prolactin values in 2523 women with various menstrual disorders. The red part of the columns indicates the number of prolactinomas. 
incidence of prolactinomas is high is supported by the findings in the 404 patients with galactorrhoea. Both groups presented a quite normal curve of prolactin frequency levels and a substantial amount of values over $30 \mu \mathrm{g} / \mathrm{L}$ ( $15 \%$ in the 201 cases with normal cycles and $42 \%$ in the 203 patients with menstrual disorders) in which 79 prolactinomas were detected (Figures $4 \mathrm{a}$ and $4 \mathrm{~b}$ ).

Based on the size of these data, it is reasonable to assume that serum prolactin values between 1 and $20 \mu \mathrm{g} / \mathrm{L}$ are normal, while those between 20 and $30 \mu \mathrm{g} / \mathrm{L}$ should be evaluated by repeating the assay and excluding macroprolactinaemia. ${ }^{7,8}$ The values over $30 \mu \mathrm{g} / \mathrm{L}$ should be considered at high risk for a prolactinoma and should be investigated further. Of 3795 women without galoctorrhoea, 97 (2.5\%) had PRL values $>30 \mu \mathrm{g} / \mathrm{L}$ and almost half of them (38) harbored a prolactinoma (Table 1 )

Among the aetiologies of hyperprolactinaemia, venepuncture stress and the polycystic ovary syndrome (PCOS) are frequently mentioned. Our results, however, do not show evidence for the existence of such relationships. In each category, $95 \%$ of the women had prolactin values in the normal range $(1-20 \mu \mathrm{g} / \mathrm{L})$ despite the fact that most of them had some degree of anxiety or nervousness at the blood-sampling. In PCOS, an incidence of hyperprolactinaemia ranging from 14 to $50 \%$ has also been reported by several authors. ${ }^{9-11}$ In our series, normal values had $93.5 \%$ of the women with oligomenorrhoea and $89.5 \%$ of those with secondary amenorrhoea. The smaller percentage of normal values in the latter group was due to a large subset $(8.1 \%)$ of values of more than $30 \mu \mathrm{g} / \mathrm{L}$ in which 14 prolactinomas were found (Table 1 ).

Epidemiological studies on the incidence of prolactinomas in the general population are rare. An estimated prevalence of 100-400 per million has been reported ${ }^{12,13}$ and a higher prevalence of 667 per $1,000,000$ was observed in a region of Belgium. ${ }^{14}$ In our series the incidence of prolactinoma in the 1272 cases with normal ovulatory cycles and no endocrine abnormality, those consulting for infertility (N:753) and those with idiopathic hirsutism (N:519) was 1:212 or 4717 per one million (6 prolactinomas). An indirect estimation of the incidence of prolactin secreting pituitary adenomas in the general population can be derived from the work of Buurman and
Saeger ${ }^{27}$ who examined the frequency of adenomas and their hormonal content by immunohistochemical methods in 3048 postmortem pituitaries and found 132 prolactin cell adenomas or $4.3 \%$ of the whole group which had a size ranging from 0.1 to 6 $\mathrm{mm}$ with a median of $1.2 \mathrm{~mm}$. This means that the prolactin cell adenomas with a size of $\geq 1.2$ to $6 \mathrm{~mm}$ were 66 in the 3048 pituitaries, a frequency that corresponds to 21,653 per million. The proportion of these prolactinomas that had a recognizable size or were hypersecreting is unknown.

The classification of a prolactinoma with a diameter equal to or less than 10 millimeters as microprolactinoma - dating back to the time of the first description of these tumors and that are still inappropriately used-serves no practical purpose in the modern era of imaging techniques. ${ }^{7,15}$ A prolactinoma measuring 6-9 millimeters, characterized as microprolactinoma, is not at all micro-that is, small - and its presence and nature present no problem of identification, as it occupies almost all the pituitary gland, the height of which averages $7.2 \mathrm{~mm} .{ }^{16,17}$ Moreover, it is associated with high prolactin values and the response to treatment is easily identified. Tumors of that size have been more appropriately characterized as mesoadenomas (medium-sized adenomas) by certain authors, a term that has been adopted in the present series. The real problem lies with small prolactinomas, those of 5 or $3 \mathrm{~mm}$ or less which represent the majority and are more difficult to recognize and differentiate from the small non-secreting tumors. In the literature, the frequency of small tumors is occasionally referred to as being $6.5 \%$ to $10 \%$ with extreme values of $22.5 \%$ and $26.7 \%$ of pituitary tumors found at autopsies, thus creating the impression of a very high incidence of these tumors without any mention of the stratification of this percentage according to the size of the tumor. In fact, in most autopsy findings it is indicated that the majority of pituitary tumors are either not visible macroscopically or are very small and, therefore, being undetectable, they should be considered clinically insignificant. ${ }^{18-22}$ This is more clearly documented in three large series comprising 9148 autopsies which reported classification of the size of the pituitary tumors and had found the frequency of tumors measuring 3-5 millimeters to be between $<0.85$ and $2.5 \% .^{23-27}$ The highest frequency $(26.7 \%)$ of pituitary tumors was reported by Barrow 

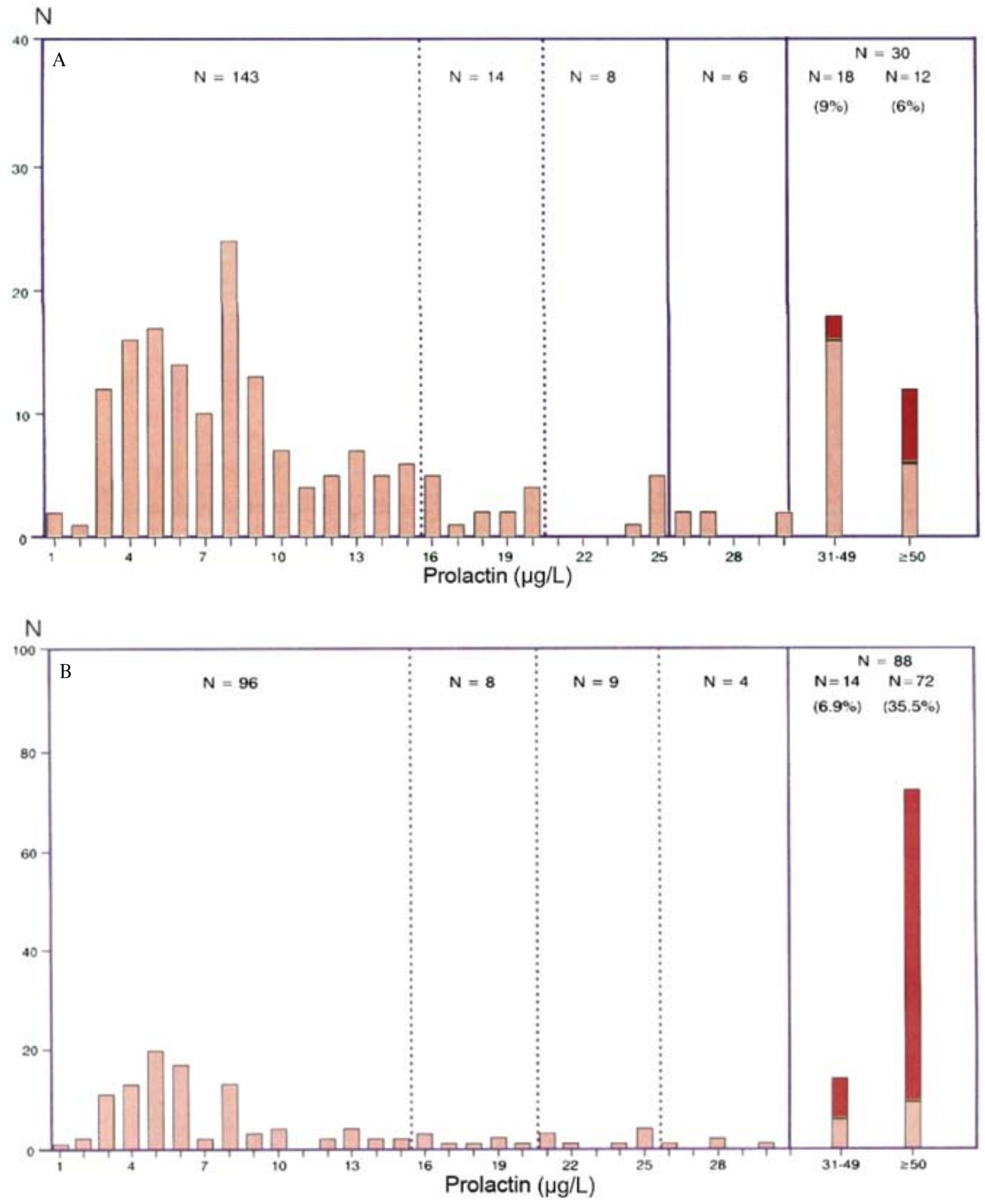

Figure 4. Frequency distribution of prolactin values in 201 women with galactorrhoea and normal menses (A) and in 203 women with galactorrhoea and menstral disorders (B). The red part of the columns indicates the number of prolactinomas. 
et $\mathrm{al}^{24}$ in 1988. However, $96 \%$ of the tumors found by these authors in 120 autopsies had a size of less than $3 \mathrm{~mm}$, that is, they were lesions which are either undetectable or difficult to distinguish from other abnormalities of the pituitary and therefore clinically nonsignificant. The difficulty of recognizing these tumors by magnetic resonance imaging (MRI) is illustrated by the findings of Hall et al ${ }^{17}$ who, in the pituitaries of 100 volunteers, detected 41 different sites of abnormalities recognized by three independent reviewers in 34 . Our series of 117 prolactinomas consisted of 104 microprolactinomas measuring 3$5 \mathrm{~mm}$, four mesoprolactinomas with a size of 6-9 mm and 9 macroprolactinomas. Of interest is the fact that a proportion of the microprolactinomas, as great as one third of them, exhibited high prolactin values similar to those of the macroprolactinomas despite their small size. The prolactinomas are considered to be common in women, with a peak incidence in the childbearing years. ${ }^{28-30}$ This is documented in our series, as in $50 \%$ of the cases the diagnosis was indeed made in the childbearing period of 23 to 33 years of age (Figure 5). However, our series revealed that actually the prolactinomas are tumors of puberty and very young women if one takes into consideration the onset symptoms of amenorrhoea, galactorrhoea or both which occurred in one third of the cases before the $20^{\text {th }}$ year of age and in half before the $23^{\text {rd }}$ year of age (Figure 5).

Medical treatment of prolactinomas represents one of the most effective therapies in endocrinology, as the majority of prolactinomas respond to the treatment favorably thus affording the endocrinologist the pleasure of helping the patient via a non-interventional therapy. ${ }^{28}$ One can imagine the satisfaction of the physician and the gratitude of the patient at the sight of a large adenoma that has shrunk within six months of treatment. Clinical practice, however, has varied considerably with regard to details of medical treatment and its follow-up because of problems related to the size of the adenoma and the concomitant hyperprolactinaemia (extensive review in reference 29).

In the large prolactinomas, medical treatment was initially given only pre-operatively to induce shrinkage of the adenoma that would facilitate its removal surgically. This practice that had provoked

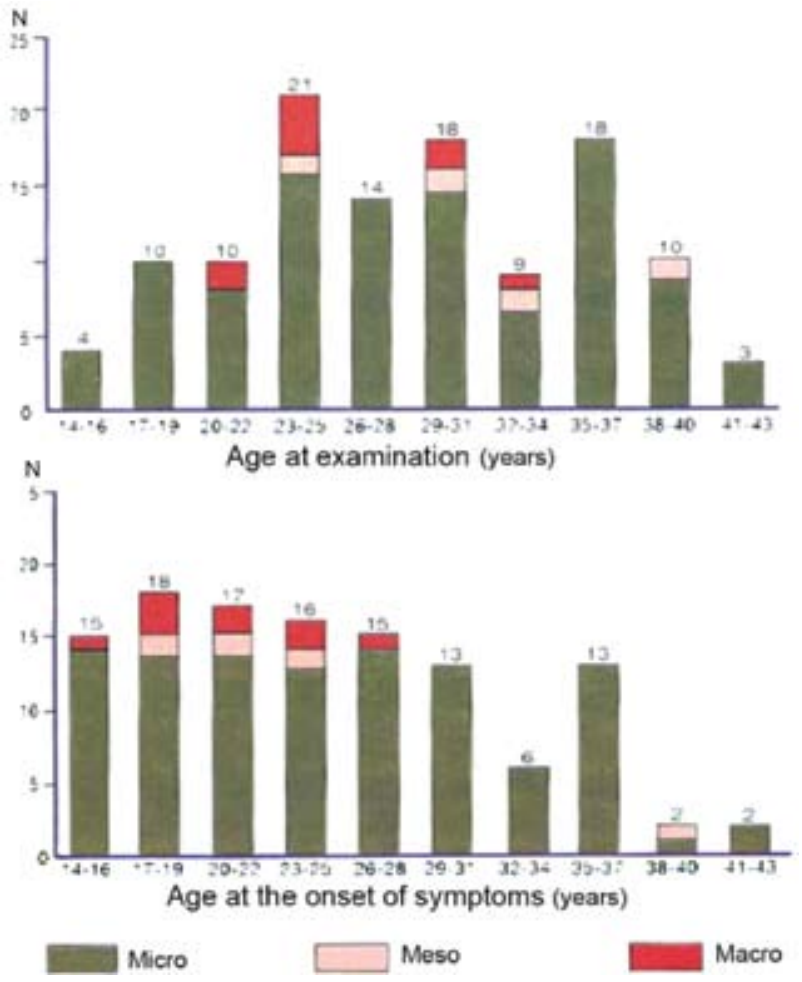

Figure 5. Prolactinomas. Distribution according to age at examination and symptoms onset. In $50 \%$ of the women with prolactinomas, the diagnosis was made at the age of 23-33 years but the onset of symptoms occurred before the age of 20 years in $30 \%$ and before the age of 23 years in $50 \%$ of the patients.

debate among neurosurgeons as to its necessity, is no longer applied, as patients with macroprolactinomas are not considered neurosurgical cases even if they have visual field defects. ${ }^{30}$

Because of its remarkable effectiveness, medical treatment of the microprolactinomas with dopamine agonist was continued for years. However, in the 1980s a series of papers appeared that had studied the natural history of a total of 139 untreated microadenomas, indicating that for a period of observation of 2.5 to 8 years only nine of them $(6.5 \%)$ showed evidence of growth. ${ }^{29,31-33}$ These results indicated that treatment of microprolactinomas to prevent them from growing does not constitute an absolute indication. This assumption was crystallized in the diagnostic algorithm proposed by the committee of experts formed by the Pituitary Society in 2005 which recommends only follow-up for microprolactinomas with hyperprolactinaemia and without symptoms. ${ }^{30}$ The same committee advises that "women with nor- 
mal menstrual cycles or postmenopausal women who have microprolactinomas with tolerable galactorrhoea should be reassured and not actively treated". These guidelines, however, do not take into consideration the size of a microprolactinoma nor the level of hyperprolactinaemia, two factors that influence the therapeutic approach. On the other hand, the presence of galactorrhoea cannot be ignored as it is not only bothersome but it testifies that the excess of prolactin is exerting its biological effect at least on one of its multiple targets, the breast, and perhaps on others that are subclinical and unidentified. It is therefore advisable to treat both the macro- and the microprolactinomas, even those measuring a few millimeters, with the aim of reducing hyperprolactinaemia and achieving the greatest reduction of the size of the adenomas.

Nevertheless, this decision is related to two problems: firstly and more importantly the duration of treatment, and secondly the potential adverse effects of a long-term treatment with a dopamine agonist. The duration of medical treatment is currently the main challenge in the management of prolactinomas. ${ }^{29}$ Studies in which discontinuation of treatment was attempted showed a great spectrum of results, as normoprolactinaemia was maintained from as low as 0 to $6 \%$ to as high as 50 to $60 \%$ of cases over a period of 12 to 60 months after withdrawal. ${ }^{34-38}$ Drawing conclusions from these studies is difficult because not all were prospective and most of them included micro- and macroadenomas and patients who had undergone neurosurgery or had received radiotherapy. However, certain of these studies observed that post-withdrawal hyperprolactinaemia was lower than that at the onset of treatment and that extending the period of treatment with dopamine agonists resulted in longer phases of remission. Taking into consideration all these parameters, one can formulate a rational therapeutic approach. In the macroadenomas and the large mesoadenomas that experience normalization of prolactin levels during treatment but small - up to $20 \%$ - reduction of their size, therapy should be continued for many years, as it is likely that discontinuation of treatment will have an unfavorable result. In the prolactinomas that show significant shrinkage, treatment should be continued for two to three years, after which a progressive reduction of the dose could be tried until normoprolactinaemia is maintained with the lowest dose and then cessation of treatment can take place followed by periodic monitoring. Tapering the dose has a prognostic value because if normoprolactinaemia is maintained with a small dose it is more likely that post-withdrawal prolactin levels will remain low. Resistance, more commonly partial, to treatment is observed in 10 to $20 \%$ of the cases and can be dealt with by increasing the dose. ${ }^{39}$ Somatostatin analogues and mixed compounds with somatostatin and dopamine action have been investigated in the treatment of resistant cases, with poor results. ${ }^{29}$

Another problem related to the medical treatment of prolactinomas is the fact that the patients, the majority of them young, will be receiving a dopamine agonist for many years. Extensive clinical experience with these drugs exists from their use in Parkinson disease and in other neurological conditions. Common side effects associated with the use of bromocryptine and cabergoline, like nausea, headaches and dizziness, are not severe and can be avoided by starting with a small dose and progressively increasing it and they usually subside with continued use. Over the last few years, however, increased risk of cardiac valve disease has been reported in patients with Parkinson disease receiving high doses of dopamine agonists ranging cumulatively from 2579 to $6677 \mathrm{mg}$ for a period of 2-4 years. This raised concern about the incidence of these side effects in patients with prolactinomas, which is illustrated in a recent commentary that analyzed six papers all published in 2008 studying this issue. ${ }^{40}$ Four of them did not show clinically relevant valvular regurgitation but in two mild tricupid and mitral insufficiency was found, leaving this important subject open to future investigation. In patients, however, receiving high doses of the drug it is prudent to take into consideration this potentiality.

\section{SYNOPSIS AND CONCLUSIONS}

Analysis of data from our laboratory on 4199 prolactin assays and 117 prolactinomas permit the following conclusions.

Persistent prolactin levels of more than $30 \mu \mathrm{g} / \mathrm{L}$, if macroprolactinaemia is excluded, should be investigated with MRI as in this range of prolactin values the 
prolactinomas are not rare $30 \%$ in normal women, $41.5 \%$ in women with menstrual disorders, $37.5 \%$ in galactorrhoea with normal cycles and $80 \%$ in galactorrhoea associated with menstrual disorders).

The fact that $95 \%$ of the subjects in each category of our patients had prolactin values in the normal range $(1-20 \mu \mathrm{g} / \mathrm{L})$ militates against an influence on prolactin levels by venepuncture stress or the polycystic ovary syndrome presented by the majority of the 1440 patients with oligomenorrhoea and by many of the 553 patients with secondary amenorrhoea.

The characterization of prolactinomas with a size of $<10 \mathrm{~mm}$ as microprolactinomas is anachronistic and inappropriate because mesoadenomas measuring $6-9 \mathrm{~mm}$ and occupying all the pituitary gland are not micro (small) and should be dealt with accordingly. The real microprolactinomas are those with a size of $3-5 \mathrm{~mm}$ which are by far more frequent and present problems of identification.

In three large series of 9148 autopsies, the incidence of pituitary tumors of $3-5 \mathrm{~mm}$ diameter was small $(0.65-2.5 \%)$. Such adenomas will be considered prolactinomas if they are accompanied by hyperprolactinaemia. In our series, the majority of prolactinomas (104 of 117) were 3-5mm and their overall frequency in 1272 women with normal cycles and no endrocrine abnormality was $0.47 \%$ (or 4717 per million). In 2523 women with menstrual disorders, the frequency was $1.26 \%$, in 201 women with galactorrhoea and normal cycles $3.9 \%$ and in 203 with galactorrhoea and menstrual disorders $34.9 \%$.

One third of the prolactinomas measuring 3-5mm had prolactin values in the range of macroprolactinomas despite their small size.

The data of our series indicate that the prolactinomas represent tumors of puberty and of very young women, as the clinical symptoms were first-apparent in one third of the cases before the age of 20 years and in half of them before the age of 23 years.

\section{REFERENCES}

1. Molitch ME, 1995 Prolactinoma. In Melmed S (ed) The pituitary. Blackwell Science Inc; pp, 443-477.

2. Chahal J, Schlechte J, 2008 Hyperprolactineamia. Pituitary 11: 141-146.
3. Mancini T, Casanueva FF, Giustina A, 2008 Hyperprolactinemia and prolactinomas. Endocrinol Metab Clin N Am 37: 67-99.

4. Schlechte JA, 2003 Clinical practice. Prolactinoma. N Engl J Med 349: 2035-2041.

5. Batrinos ML, Panitsa-Faflia Ch, Tsiganou E, Liapi Ch, 1992 Incidence and Characteristics of Microprolactinomas (3-5mm) in 4199 Women Assayed for Prolactin. Horm Metab Res 24: 384-391.

6. Batrinos M, Panitsa-Faflia Ch, Tsiganou E, Pitoulis G, Liapi Ch, 1994 Contribution to the problem of Hyperprolactinaemia: Experience with 4.199 Prolactin assays and 117 prolactinomas. Int J Fertil 39: 120-127.

7. Hauache OM, Rocha AJ, Maia Jr, Maciel RMB, Vieira JGH, 2002 Screening for macroprolactinaemia and pituitary imaging studies. Clin Endocrinol 57: 327-331.

8. Vallette-Kasic S, Morange-Ramos I, Selim A, et al, 2002 Macroprolactinemia revisited: A study on 106 patients. J Clin Endocrinol Metab 87: 581-588.

9. Brucero N, Zecur HA, 2001 Polycystic ovary syndrome and hyperprolactinemia. Obstet Gynecol Clin North Am 28: 77-84.

10. Filho RB, Domingues L, Naves L, Ferraz E, Alves A, Casulari LA, 2007 Polycystic ovary syndrome and hyperprolactinemia are distinct entities. Gynecol Endocrinol 23: 267-272.

11. Cortet-Rudelli C, Sapin R, Bonneville JF, Brue T, 2007 Etiological diagnosis of hyperprolactinemia. Ann Endocrinol (Paris) 68: 98-105.

12. Davis JR, Farrell WE, Clayton RN, 2001 Pituitary tumours. Reproduction 121: 363-371.

13. Ciccarelli A, Daly AF, Beckers A, 2005 The epidemiology of prolactinomas. Pituitary 8: 3-6.

14. Daly AF, Rixhon M, Adam C, Dempegioti A, et al, 2006 High prevalence of pituitary adenomas: a cross-sectional study in the presence of Liege Belgium. J Clin Endocrinol Metab 91: 4769-4775.

15. Bayrak A, Saadat P, Mor E, Chong L, Paulson RJ, Sokol RZ, 2005 Pituitary imaging is indicated for the evaluation of hyperprolactinemia. Fertile Steril 84: 181-185.

16. Wolpert SM, Molitch ME, Goldman JA, Wood JB, 1984 Size, shape, and appearance of the normal female pituitary gland. Am J Roentgenol 143: 377-381.

17. Hall WA, Luciano MG, Doppman JL, Patronas J, Oldfield EH, 1994 Pituitary magnetic resonance imaging in normal human volunteers: Occult adenomas in the general population. Ann Int Med 120: 817-820.

18. Costello RT, 1936 Subclinical adenoma of the pituitary gland. Am J Pathology 12: 205-216.

19. McCormick WF, Halmi NS, 1971 Absence of chromophobe adenomas from a large series of pituitary tumors. Arch Pathol 92: 231-238.

20. Parent AD, Bebin J, Smith RR, 1981 Incidental pituitary adenomas. J Neurosurg 54: 228-231.

21. Muhr C, Bergstrom K, Grimelius L, Larsson SG, 1981 Parallel study of the sella turcica and the histopathol- 
ogy of the pituitary gland in 205 autopsy specimens. Neuroradiology 21: 55-65.

22. El-Hamid MW, Joplin GF, Lewis PD, 1988 Incidentally found small pituitary adenomas may have no effect on fertility. Acta Endocrinol 117: 361-364.

23. Kovacs K, Ryan N, Horvath E, Singer W, Erzin C, 1980 Pituitary adenomas in old age. J Gerontol 35: 16-22.

24. Burrow GN, Wortzman G, Rewcastle NB, Holgate RC, Kovacs K, 1981 Microadenomas of the pituitary and abnormal sellar tomograms in an unselected autopsy series. N Engl J Med 304: 156-158.

25. Von Schvenziger G, Warzok IZ, 1981 Hyperplasien und adenoma der hypophyse in uuselectierten sections gut. Zbl Allg Pathol u Pathol Ahat 126: 495-498.

26. Teramoto A, Hirakava K, Sann N, Osamura Y, 1994 Incidental pituitary tumors in 100 unselected autopsy specimens. Radiology 193: 161-164.

27. Buurman H, Saeger W, 2006 Subclinical adenomas in post-mortem pituitaries: classification and correlations to clinical data. Eur J Endocrinol 154: 753-758.

28. Schlechte JA, 2007 Long-term management of prolactinomas. J Clin Endrocrinol Metab 92: 2861-2865.

29. Gillam Mp, Molitch ME, Lombardi G, Colao A 2006 Advances in the treatment of prolactinomas. Endocr Rev 27: 485-534.

30. Casanueva FF, Molitch ME, Schlechte JA, et al, 2006 Guidelines of the pituitary society for the diagnosis and management of prolactinomas. Clin Endocrinol 65: 265273.

31. Weiss MH, Teal J, Gott P, et al, 1983 Natural history of microprolactinomas: six years follow-up. Neurosurgery 12: 180-183.

32. Schlechte J, Dolan K, Sherman B, Chapler F, Luciano A,
1989 The natural history of untreated hyperprolactinemia: a prospective analysis. J Clin Endocrinol Metab 68: 412-418.

33. Schlechte J, Dolan K, Sherman B, Chapler F, Luciano A, 1989 The natural history of untreated hyperprolactinemia: a prospective analysis. J Clin Endcrinol and Metab 68: 412-418.

34. Passos VQ, Souza JJ, Musolino NR, Bronstein MD, 2002 Long-term follow-up of prolactinomas: normoprolactinemia after bromocriptine withdrawal. J Clin Endocrinol Metab 87: 3578-3582.

35. Colao A, Di Sarno A, Coppabianca P, De Somma C, Pivonello R, Lombardi G, 2003 Withdrawal of longterm carbegoline therapy for tumoral and nontumoral hyperprolactinemia. N Engl J Med 349: 2023-2033.

36. Colao A, Di Sarno A, Cappabianca P, Di Somma C, Pivonello R, Lombardi G, 2003 Withdrawal of longterm cabergoline therapy for tumoural and nontumoural hyperprolactinaemia. N Engl J Med 349: 2023-2033.

37. Biswas M, Smith J, Jadon D, et al, 2005 Long-term remission following withdrawal of dopamine agonist therapy in subjects with mircroprolactinemia. Clin Endocrinol (Oxf) 63: 26-31.

38. Colao A, Di Sarno A, Guerra E, et al, 2007 Predictors of remission of hyperprolactinemia after long-term withdrawal of cabergoline therapy. Clin Endocrinol (Oxf) 67: 426-433.

39. Molitch ME, 2003 Dopamine resistance of prolactinomas. Pituitary 6: 19-27.

40. Kars M, Pereira AM, Romijin JA, 2008 Cabergoline and cardiac valve disease in prolactinoma patients: additional studies during long-term treatment are required. Eur J Endocrinol 159: 363-367. 